\title{
Analysis of Large-Strain Extrusion Machining with Different Chip Compression Ratios
}

\author{
Wen Jun Deng, Ping Lin, Zi Chun Xie, and Qing Li \\ School of Mechanical and Automotive Engineering, South China University of Technology, 381 Wushan Road, Tianhe District, \\ Guangzhou 510641, China
}

Correspondence should be addressed to Wen Jun Deng, dengwj@scut.edu.cn

Received 20 May 2012; Revised 12 August 2012; Accepted 12 August 2012

Academic Editor: Sheng-Rui Jian

Copyright ( $\odot 2012$ Wen Jun Deng et al. This is an open access article distributed under the Creative Commons Attribution License, which permits unrestricted use, distribution, and reproduction in any medium, provided the original work is properly cited.

Large-Strain Extrusion Machining (LSEM) is a novel-introduced process for deforming materials to very high plastic strains to produce ultra-fine nanostructured materials. Before the technique can be exploited, it is important to understand the deformation behavior of the workpiece and its relationship to the machining parameters and friction conditions. This paper reports finiteelement method (FEM) analysis of the LSEM process to understand the evolution of temperature field, effective strain, and strain rate under different chip compression ratios. The cutting and thrust forces are also analyzed with respect to time. The results show that LSEM can produce very high strains by changing in the value of chip compression ratio, thereby enabling the production of nanostructured materials. The shape of the chip produced by LSEM can also be geometrically well constrained.

\section{Introduction}

Deforming metallic alloys to very high plastic strains is known to confer significant benefits to the material, including microstructural refinement and enhanced mechanical and physical properties [1-3]. Until now, various techniques have been developed to deform metallic alloys, of which, the equal channel angular extrusion (ECAE) process has been found to be very effective. Figure 1 shows the schematic of the ECAE process. During the process, a billet is pressed through a constrained channel, which intersects another channel of identical cross-sectional shape. When the billet passes through the intersection of these channels, it undergoes a large shear strain along the plane of intersection.

ECAE is, however, not without limitations. Multiple passes of deformation are required to create large accumulated strains. Moderate- and high-strength metals and alloys are difficult to deform at ambient temperatures by ECAE due to constraints imposed by the forming equipment, such as durability of tools and dies. Finally, there are uncertainties pertaining to knowledge and control of deformation field parameters [4].

These problems have been solved in large-strain extrusion machining where the chip formation is just partially constrained so that different strains can be imposed on the machined chip. The machining parameters can be easily adjusted with external requirements. Thus, ultra-fine materials can be formed in a single pass. Figure 2 shows a schematic of a plane-strain LSEM process. The LSEM tool consists of two main components: a bottom section with a sharp cutting edge inclined at a rake angle $\alpha$ and a top section that acts as a constraining edge. During the LSEM process, this chip compression ratio $(\lambda)$ is given by

$$
\lambda=\frac{t_{\mathrm{ch}}}{t_{d}},
$$

where $t_{d}$ is the thickness of the undeformed chip removed from the workpiece which itself is a chip with predetermined thickness, $t_{\mathrm{ch}}$. The geometry of the chip is controlled at the point of its formation by the constraining tool. The chip compression ratio and shear strain are the most important parameters used to characterize the deformation in the chip. Figure 3 shows the setup for LSEM. Both $t_{d}$ and $t_{\text {ch }}$ can be changed by adjusting shims and the three setting screws are designed to reinforce machine parts to keep the LSEM operative.

Much effort has been expended on understanding the factors that influence properties of the ECAE billets. There 


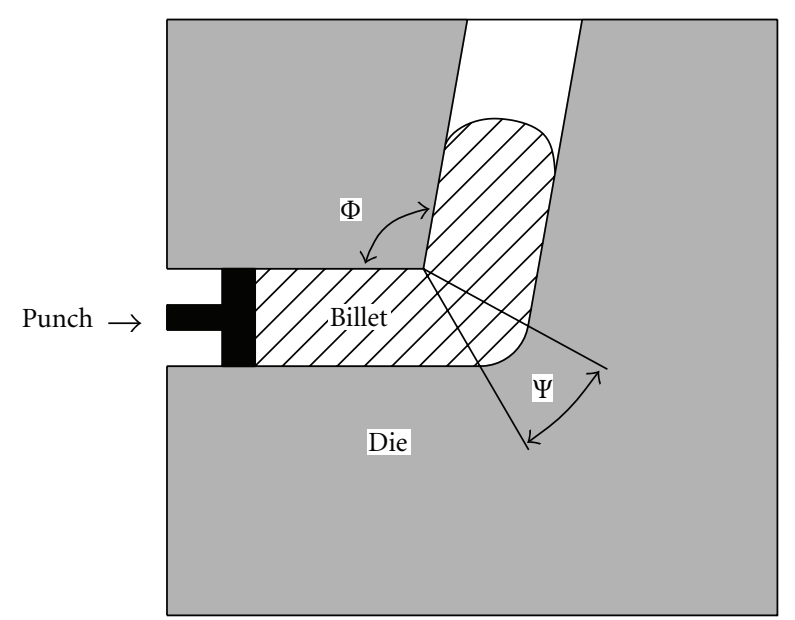

FIGURE 1: Schematic of ECAE and associated geometric parameters.

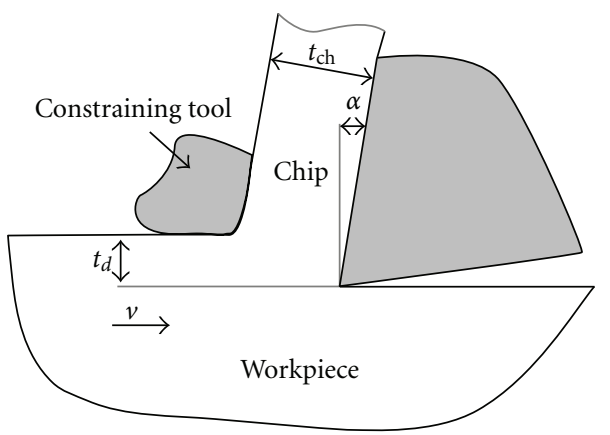

FIGURE 2: Schematic of LSEM and associated geometric parameters.

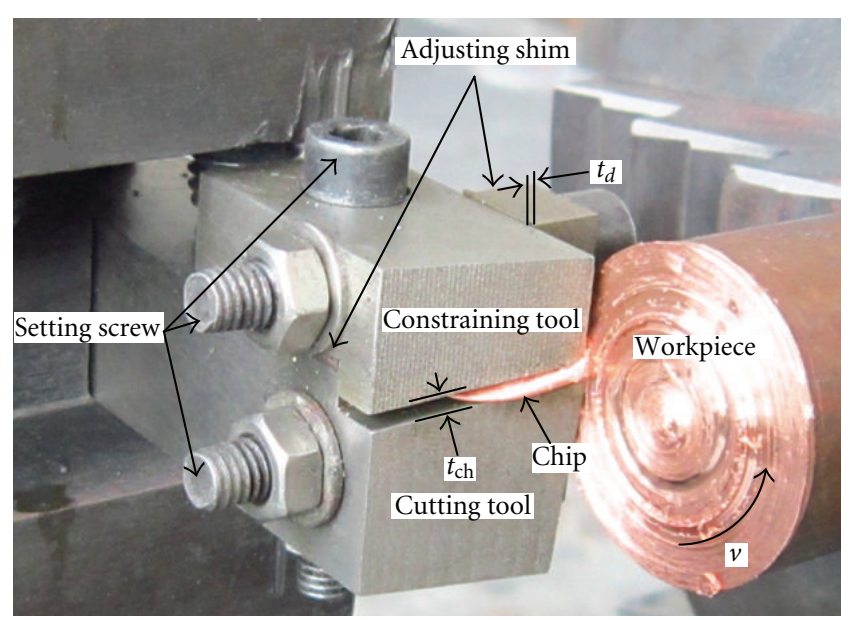

FIGURE 3: Setup for LSEM.

have been reports of studies on the effect of routes $[5,6]$, ram speed [7], die tooling [8-10], friction conditions [11], extrusion temperature $[12,13]$, and material properties [14] on the characteristics of the billets. Finite-element methods (FEMs) that analyze deformation behavior and the fundamental mechanism of formation of ultrafine grain structure during the ECAE process have also been reported [15].
There are, however, very few studies on large strain machining that can help understand the effect of process parameters on material behavior. Chiffre [16] originally proposed the idea of extrusion cutting to produce soft metal chips with geometrically controlled chip formation at high machining speed. He also proposed a simple upper bound model for estimating strain in the chip. This shear strain imposed in plane strain LSEM by combined machining and extrusion depends only on the rake angle and the chip compression ratio defined in (1). This effective strain $\left(\varepsilon_{\text {eff }}\right)$ may be expressed as

$$
\varepsilon_{\text {eff }}=\frac{\gamma}{\sqrt{3}}=\frac{((\lambda / \cos \alpha)+(1 / \lambda \cos \alpha)-2 \tan \alpha)}{\sqrt{3}},
$$

where $\gamma$ is the shear strain, $\alpha$ is the tool rake angle, and $\lambda$ is the chip compression ratio [16]. An investigation was carried out on ascertaining the feasibility of using extrusion cutting as a continuous manufacturing process for brass strip production.

Hoshi and Shaw [17] developed a method for producing wire in which cutting and forming are combined into one operation. A chip is first formed by cutting a billet with a special tool containing a hole into which the chip flows. This hole acts as a die to convert the rectangular chip into a round wire. Shet and Deng [18] developed a finite-element model to simulate and analyze the orthogonal metal cutting process under plane strain conditions, with focus on the residual stress and strain fields in the finished workpiece. Davim and Maranhão [19] employed the finiteelement method to determine the plastic strain and plastic strain rate when machining AISI 1045 steel and concluded that both plastic strain and plastic strain rate can be predicted with good precision when machining with the FEM model. Swaminathan et al. [20] described important aspects of the large strain deformation field in machining and established that controlled shear strains in the range of 1-15 can be imposed on the chip in a single pass of plane-strain machining, and the microstructure of the chip is substantially finer than that of the bulk material. The features of this severe plastic deformation (SPD) approach were illustrated by its application to the study of formation of ultra-fine-grained (UFG) and nanocrystalline microstructures in various alloys. Lee et al. [21] described a method for measurement of velocity and strain distributions in planestrain two-dimensional machining. The key elements of the experimental approach were the use of an optically transparent Sapphire tool for chip formation and the application of a charge-coupled-device- (CCD-) based, high-speed imaging system to directly observe and record material flow in the primary and secondary (rake face) deformation zones, during machining. By combining the observations with image analysis methods, the velocity, strain rate, and strain distributions in chip formation were directly estimated. Shankar et al. [22] presented the properties of aluminum 6061 alloys of various tempers, severely deformed in plane strain at room temperature by machining, and demonstrated the effectiveness of plane strain machining as a technique for studying large strain deformation of aluminum alloys in various tempers. A variety of strains, microstructures, 
and mechanical properties were obtained by appropriate choice of the tool rake angle. Furthermore, large strains were imposed in a single pass of deformation. Deng et al. [23] studied structure refinement and deformation behavior in plane-strain machining and found that it was feasible to consider machining for the fabrication of ultra-fine-grained materials. It can be concluded that the machined chip is ultra-fine-grained material and machining can be taken as a potential severe plastic deformation method to produce ultra-fine-grained/nanostructured materials.

Plane strain (2D) machining is a potentially attractive route to creating very large plastic strains in a single stage of deformation [23, 24], while simultaneously overcoming the limitations of the SPD. Large-strain machining is also used as an SPD method since it allows a wide range of deformation conditions to be imposed even in materials of high strength and limited ductility. Since chip formation is unconstrained, the strain rate can be varied over a wide range during machining by varying the machining speed and rake angle $[21,25]$. However, this very lack of constraint in chip formation also makes it difficult to control the shape and dimensions of the resulting fine-grained material.

Large-strain extrusion machining is a newly introduced process which can be described as cutting method where the rear surface of the chip is constrained by a constraining tool such that the material is extruded through the gap between the constraining tool and cutting tool $[16,26]$. With simultaneous shape and dimensional control of extrusion in a single-step deformation process, LSEM overcomes the lack of geometric control in chip formation and leads to a greater strain than conventional machining.

This paper reports the results of an FEM analysis that studied the effects of different chip compression ratios on the LSEM process. In addition, the mechanism of LSEM process for pure copper material was described by the FEM. A series of simulation results of temperature field, effective strain, strain rate, and cutting forces were obtained. The difference between LSEM and conventional machining process was also investigated. The numerical and experimental results provided useful theoretical and experimental guidelines for LESM process.

\section{Finite-Element Models}

The finite-element model of LSEM described here is a key element in establishing plane strain machining as a process for making nanostructured materials. In the present study, the simulations were conducted with a commercial FEM code DEFORM-2D, which is based on an updated Lagrangian formulation for large plastic deformation analysis. The chip formation process was simulated as plastic flow and the separation of the chip material from the workpiece was achieved by continuous remeshing. The initial workpiece mesh and tool mesh are shown in Figure 4. During the process, the workpiece moves in certain speed while the cutting and constraining tools are stationary. The cutting and constraining tools, assumed to be much harder than the workpiece material, with no permissible rotation or

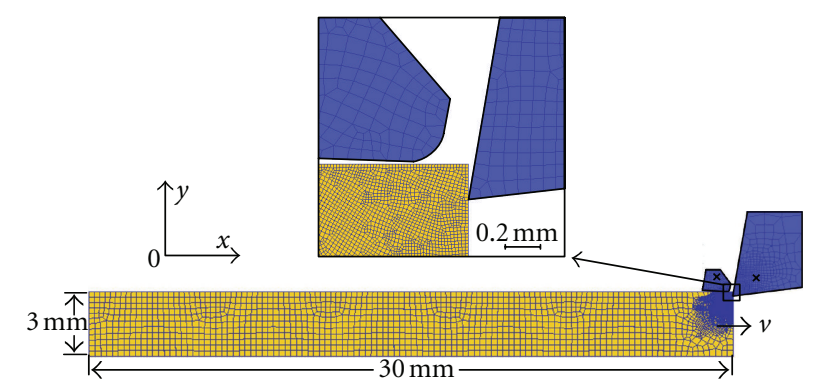

FIGURE 4: Finite-element model.

displacement, were modeled as a rigid and heat transfer body. Since the bottom and the left boundary of the workpiece were expected to undergo very little deformation during cutting, it was assigned zero displacement in the $y$ directions.

The LSEM conditions that were employed in the simulations are as follows: the cutting velocity $v$ was $0.052 \mathrm{~m} / \mathrm{s}$; the undeformed chip thickness was $0.20 \mathrm{~mm}$ and the width of the cut was $1.0 \mathrm{~mm}$; the length of cut was $2 \mathrm{~mm}$; the rake angle was $10^{\circ}$ and the environment temperature was $20^{\circ} \mathrm{C}$. The workpiece was made of pure copper and had the following properties. Young's modulus: $120 \mathrm{GPa}$, Yield stress: $150 \mathrm{MPa}$, and Possion's ratio: 0.3 . The chip compression ratio $\lambda$ varied from 0.5 to 1.9. For larger values of $\lambda$, predefined chip geometry was found to be detrimental to the simulation as the chip's outer edge became separated from the constraining tool. An upper limit for $\lambda$ occurred when the deformation of the chip was not sufficiently large for its rear surface to reach the constraining tool. In the finite-element simulation, this result occurred for $\lambda=1.925$ in extrusion machining. The cutting process was simulated from the time the tool entered the cut to the time the length of the cut was $2 \mathrm{~mm}$. In this study, chip separation was achieved through the function of adaptive remeshing strategy.

\section{Results and Discussions}

3.1. Temperature Distribution. It is important to understand the interactive effects of strain rate, strain, and temperature on microstructure refinement. The measurement of temperature is useful to study phenomena such as dynamic recovery and recrystallization. Figure 5 shows the distribution of temperature through the chip and workpiece in conventional machining and LSEM, where the compression ratio is different. A series of comparisons was performed in order to determine the difference between LSEM and conventional machining. Since the speed of machining $(v)$ influences the deformation zone temperature, by cutting at very low speeds $(\sim 0.052 \mathrm{~m} / \mathrm{s})$, this temperature can be kept marginally above the ambient temperature while imposing large strains. The maximum temperature rise in the workpiece in all cases of simulation is less than $68^{\circ} \mathrm{C}$, which is far less than the transformation temperature. The maximum temperature in LSEM is about $68^{\circ} \mathrm{C}$, a little higher than that in conventional machining $\left(\sim 63.4^{\circ} \mathrm{C}\right)$. Clearly, discernible are the strongly heated parts of the shear zone. This temperature can be 


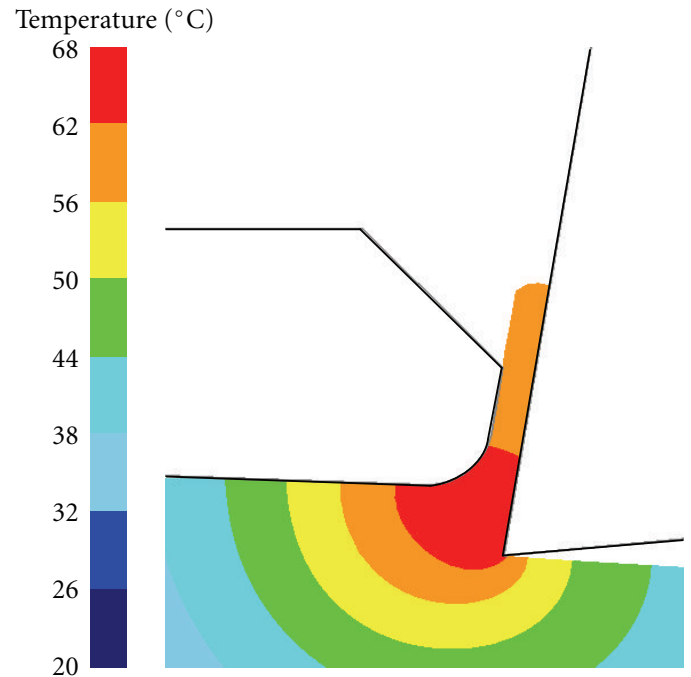

(a)

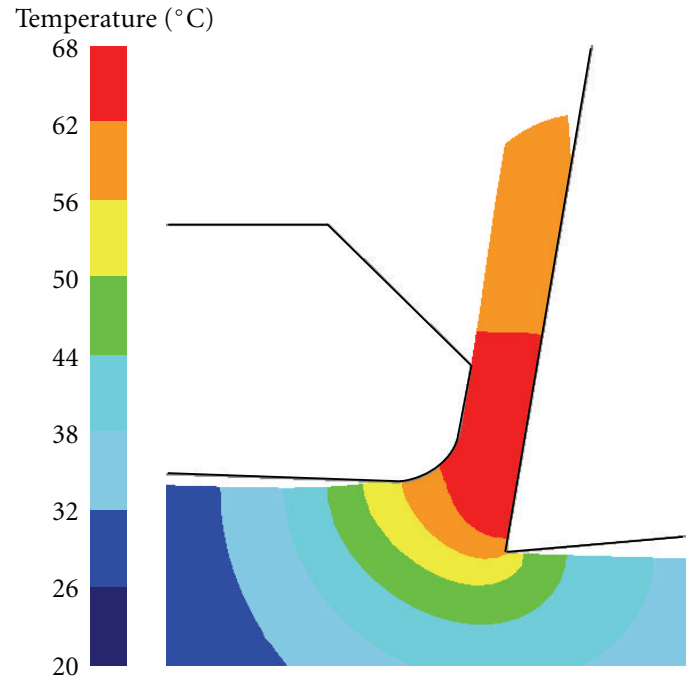

(c)

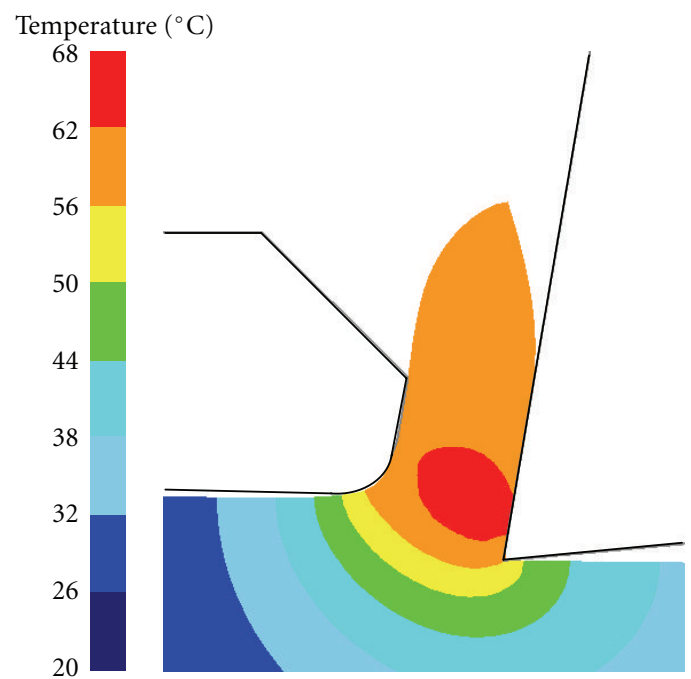

(e)

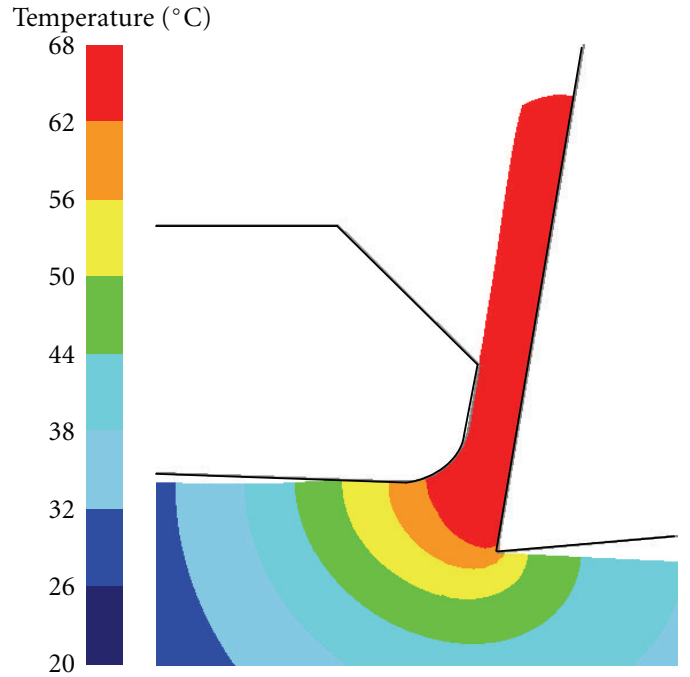

(b)

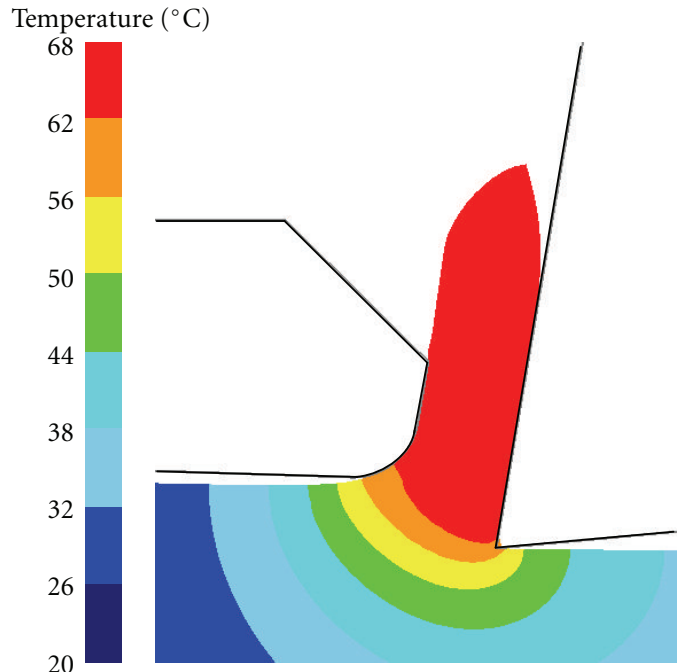

(d)

Temperature $\left({ }^{\circ} \mathrm{C}\right)$

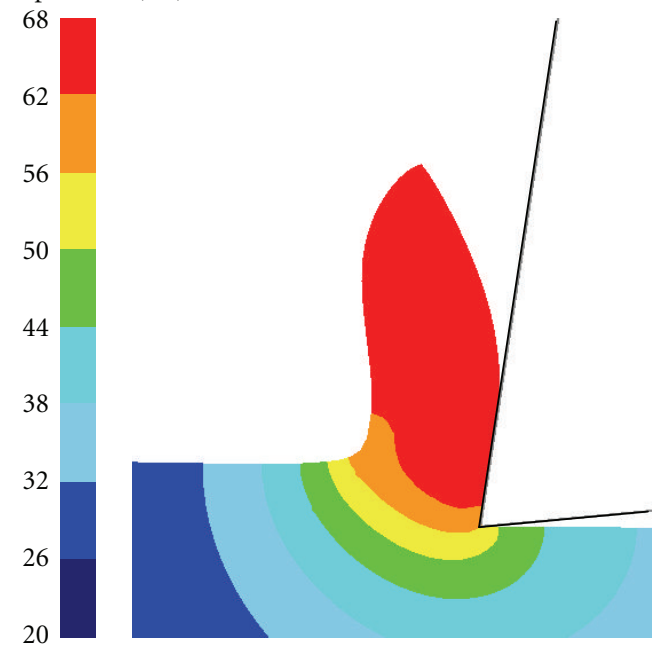

(f)

Figure 5: Temperature distributions: (a) $\lambda=0.5$; (b) $\lambda=0.75$; (c) $\lambda=1$; (d) $\lambda=1.5$; (e) $\lambda=1.9$; (f) conventional machining. 
attributed to the heat of severe shear deformation. With simultaneous shape and dimensional control of extrusion, the field of maximum temperature in LSEM is slightly larger than that in conventional machining.

3.2. Strain Distribution. Strain plays a critical role in the formation of nanomaterials in both cutting and LSEM processes. Figure 6 shows the simulated effective strain with different chip compression ratios for LSEM and for conventional machining. The variation in chip compression ratio significantly changes the magnitude of the effective strain. The maximum effective strain values are 3.64, 2.94, $2.45,2.25$, and 2.14, respectively, for chip compression ratios of $0.5,0.75,1,1.5$, and 1.9. The maximum value for the effective strain is seen to occur at $\lambda=0.5$. For $0.5<$ $\lambda<1.9$, the strain decreases with the increasing $\lambda$. It is obvious that, as $\lambda$ decreases from 1 to 0.5 , the maximum effective strain increases from 2.45 to 3.64 , representing a decrease of 1.19. However, it is also noted that, when $\lambda$ increases from 1.5 to 1.9 , the maximum effective strain decreases from 2.25 to 2.14 , a mere difference of 0.11. LSEM has the obvious advantage of producing very high strains through changes in the value of $\lambda$, compared to conventional machining. At the same time, the maximum effective strain value is only 2.23 in conventional machining, which is less than most of the other values of the LSEM. This clearly indicates that the realization of very high strains at small values of $\lambda$ is particularly interesting for causing high levels of microstructure refinement in the chip, as shown in the Figure 7.

The machining conditions are as follows: the cutting velocity $v$ is $0.052 \mathrm{~m} / \mathrm{s}$; the undeformed chip thickness is $0.2 \mathrm{~mm}$; the width of the cut is $1 \mathrm{~mm}$; the rake angle is $10^{\circ}$; the chip compression ratio is 1 . It can be observed that bulk material is composed of larger equiaxed grains with an average size greater than of $0.1 \mathrm{~mm}$ in Figure $7(\mathrm{~d})$. The sizes of the subgrains range between 200 and $800 \mathrm{~nm}$, with a mean diameter of about $400 \mathrm{~nm}$ in Figures 7(c) and 7(e). It can be concluded that both conventional machining and LSEM are effective severe plastic deformation methods to produce ultra-fine-grained/nanostructured materials. The shape of the chip obtained by LSEM can be geometrically constrained well and, therefore, may be more attractive for industrial application.

Figure 8 shows the SEM pictures of the typical morphology of a chip of pure copper produced by LSEM. The machining parameters were as follows: a cutting velocity of $0.052 \mathrm{~m} / \mathrm{s}$, a chip compression ratio $(\lambda)$ of 1.9 , an undeformed chip thickness $\left(t_{d}\right)$ of $0.1 \mathrm{~mm}$, and a tool rake angle of $+10^{\circ}$. Such a low cutting velocity was selected to ensure quasi-static deformation and to minimize temperature influences during the imposition of large strains. Figure 9 shows the microstructure of partially detached pure copper chip in conventional machining. The machining parameters used were a cutting velocity of $0.052 \mathrm{~m} / \mathrm{s}$, an undeformed chip thickness $\left(t_{d}\right)$ of $0.1 \mathrm{~mm}$, and a tool rake angle of $+10^{\circ}$. It is important to note that LSEM, unlike conventional machining, involves constrained chip formation where the deformed chip thickness is controlled a priori. This is because the constraining tool is placed such that it controls the thickness of the chip at the point of its formation. Furthermore, the surface quality of the chip in LSEM is far better than that in conventional machining. This demonstrates that significant shape change and control can also be effected by LSEM while creating bulk nanostructured materials.

Chip formation occurs by concentrated shear within a narrow deformation zone, often idealized by a "shear plane." Most of the grain refinement associated with the formation of the UFG chips has been attributed to the large shear strains imposed in this deformation zone [22]. The theoretical shear strain imposed on the chip during chip formation is given by (2) in LSEM with simplified assumptions. Figure 10 shows the distribution of effective strain through the primary deformation zone and the chip in the LSEM and conventional machining. The locations of the two trajectories $A B$ and $C D$ are shown in Figure 10(a). The starting point of the trajectory $\mathrm{AB}$, almost in the center of primary deformation zone, is just at the tool nose. The first point of the trajectory $\mathrm{CD}$ in the chip is on the rake face at $0.3 \mathrm{~mm}$ to the tool nose, while the trajectory $\mathrm{CD}$ is perpendicular to the rake face. The effective strain is relatively high near the tool nose but varying in the primary deformation zone as shown in Figure 10(b). It is easy to see that the effective strain through the primary deformation in conventional machining is far lower than any other in LSEM. It can also be seen from this figure that when the value of $\lambda$ is 0.5 , the value of effective strain is much larger than others. It can be concluded from the result that, when the value of the chip compression ratio is low, the deformation in primary deformation zone is severe. Effective strain distributions through the chip are given in Figure 10(c) for LSEM at $\lambda=$ $0.5, \lambda=0.75, \lambda=1, \lambda=1.5, \lambda=1.9$, and conventional machining. In LSEM, the deformation field adjoins the chiptool interface, wherein a significant increase in the strain is observed and is seen to extend to about a quarter of the chip thickness from the interface with the cutting tool. The strain is relatively high but varying in the secondary shear zone, subsequently leveling off to a near constant value at large distance from free surface. This is a consequence of additional straining arising from the friction at the toolchip interface. It is obvious to find that the effective strain through the thickness of the chip in conventional machining is lower than all of those in LSEM. However, it can also be seen from this figure that the effective strain curves become steeper with the decreasing $\lambda$. When the value of $\lambda$ is 1.9 , the constraining tool has little effect on the material deformation during the extrusion process, the variation of strain through the thickness of the chip is similar to that in conventional machining.

3.3. Effective Strain Rate Distribution. Figure 11 shows the simulated effective strain rates for LSEM at different chip compression ratios and for conventional machining. The strain rate contours in chip formation indicate a narrow band in machining [27]. The narrow zone, in which the effective 


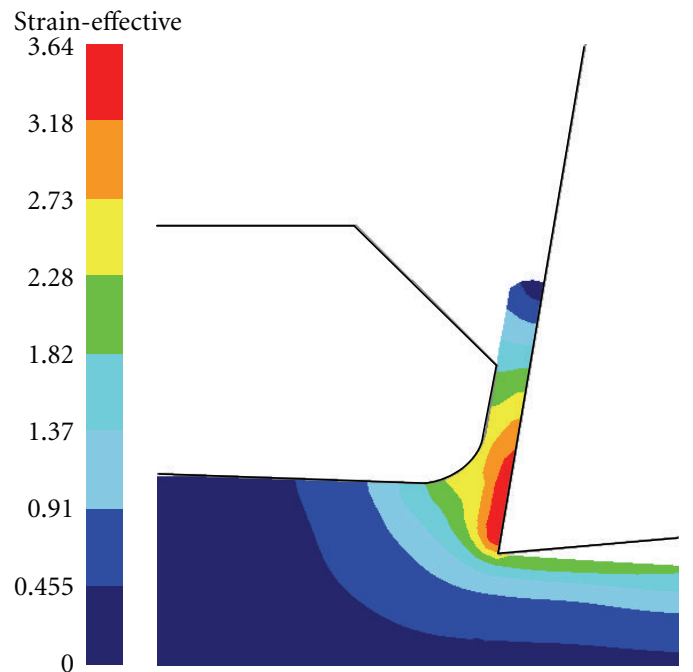

(a)

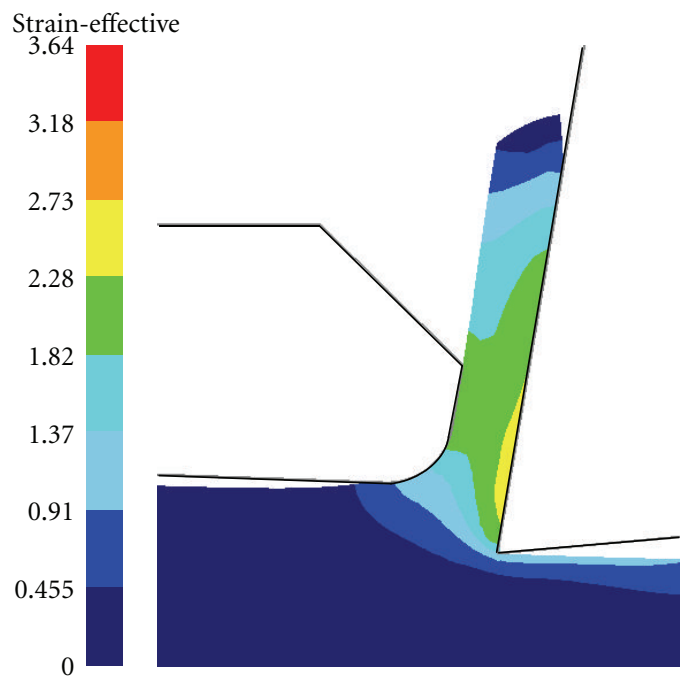

(c)

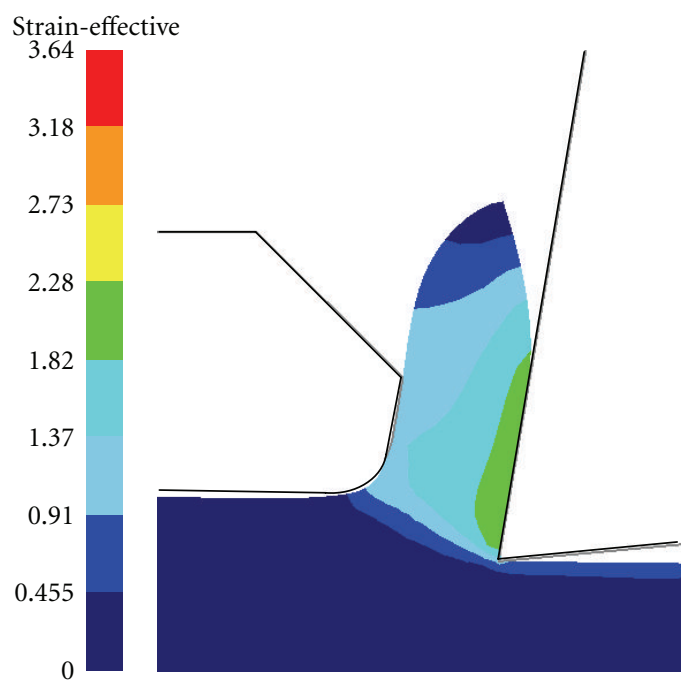

(e)

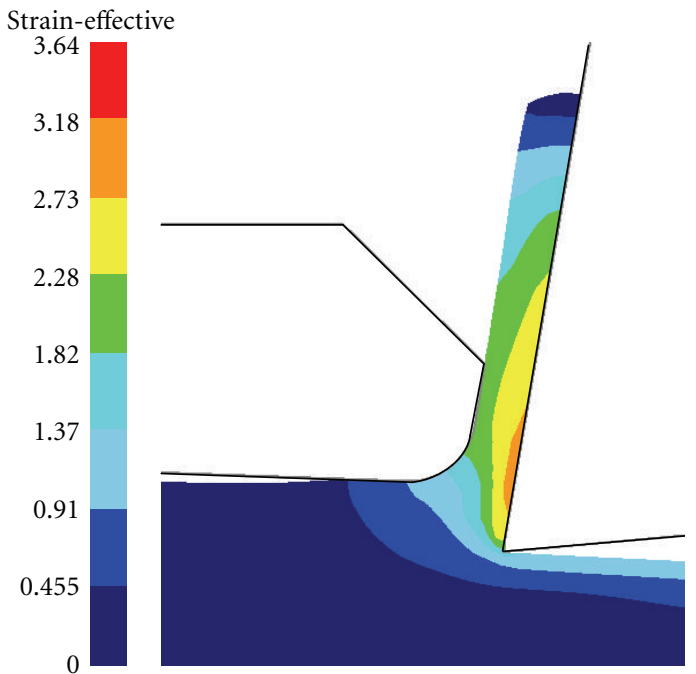

(b)

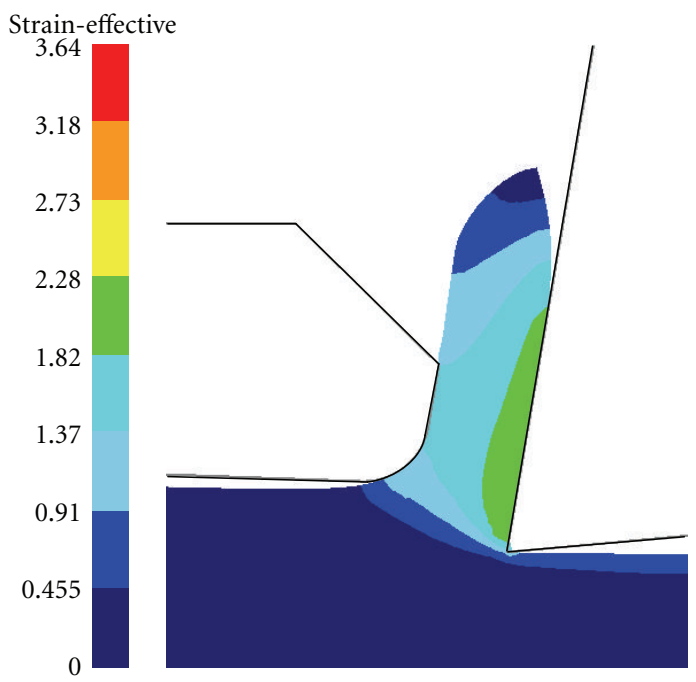

(d)

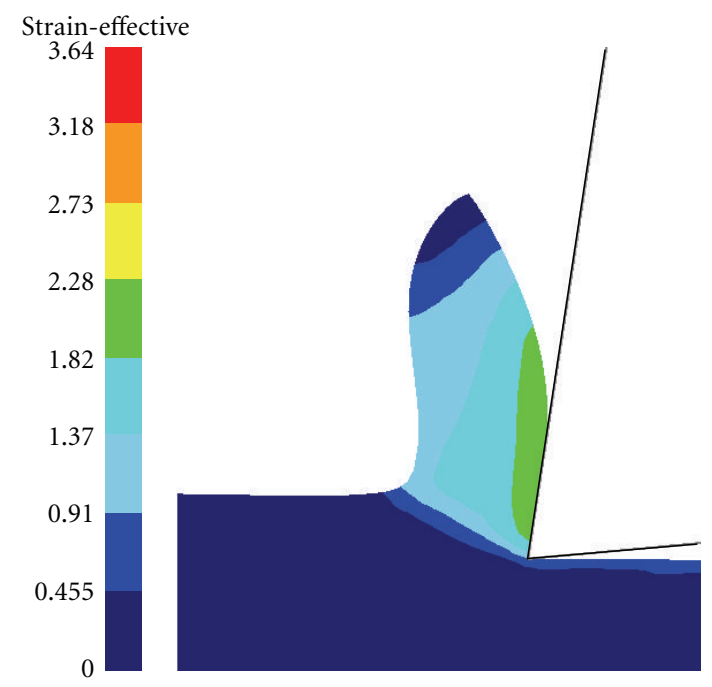

(f)

FigURE 6: Effective strain distribution in LSEM and conventional machining: (a) $\lambda=0.5$; (b) $\lambda=0.75$; (c) $\lambda=1$; (d) $\lambda=1.5$; (e) $\lambda=1.9$; (f) Conventional machining. 


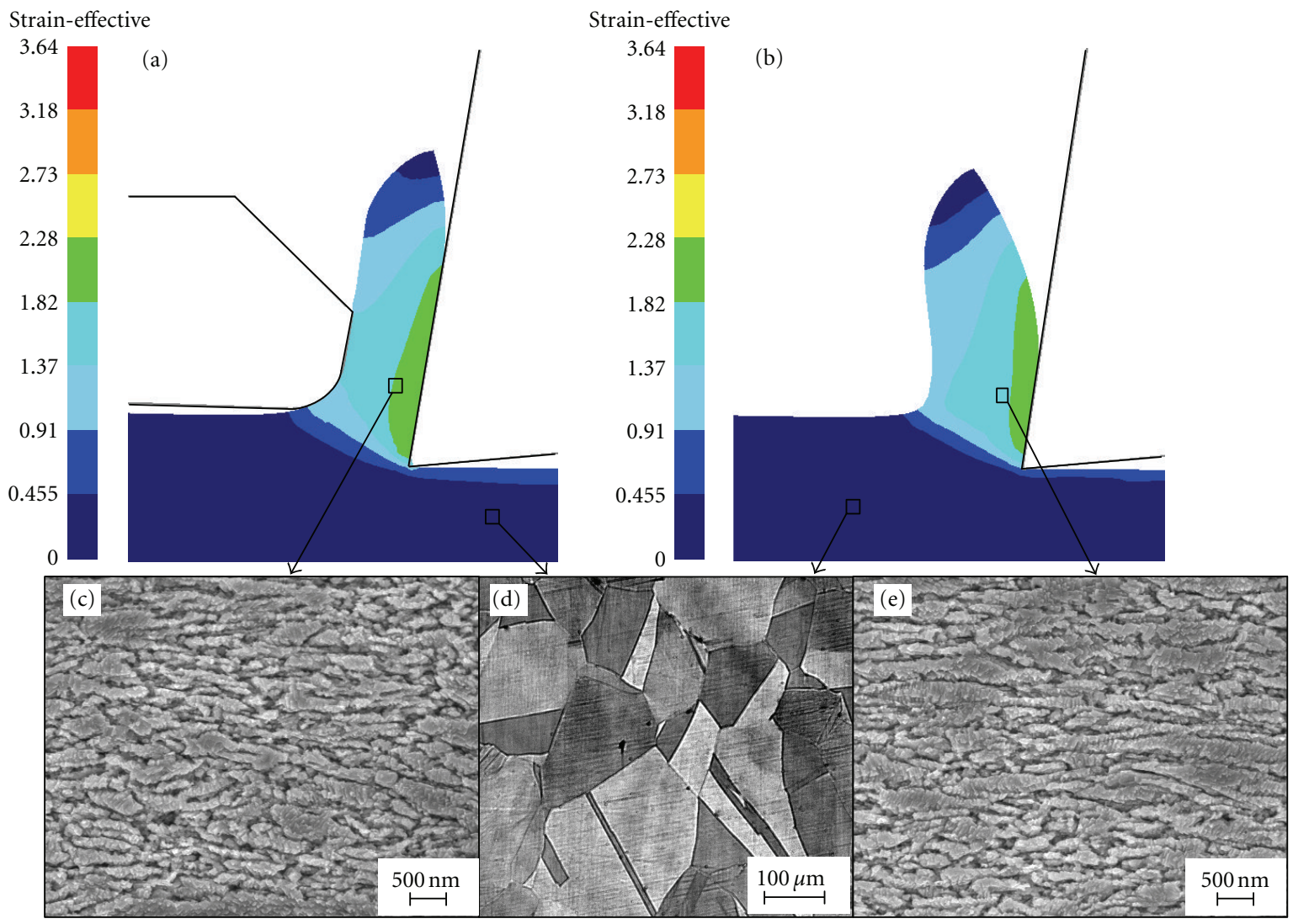

FIGURE 7: Nanostructured pure copper chip produced by LSEM and conventional machining: (a) $\lambda=1.5$; (b) conventional machining; (c) $\lambda=1.5$ chip; (d) bulk; (e) conventional machining chip.

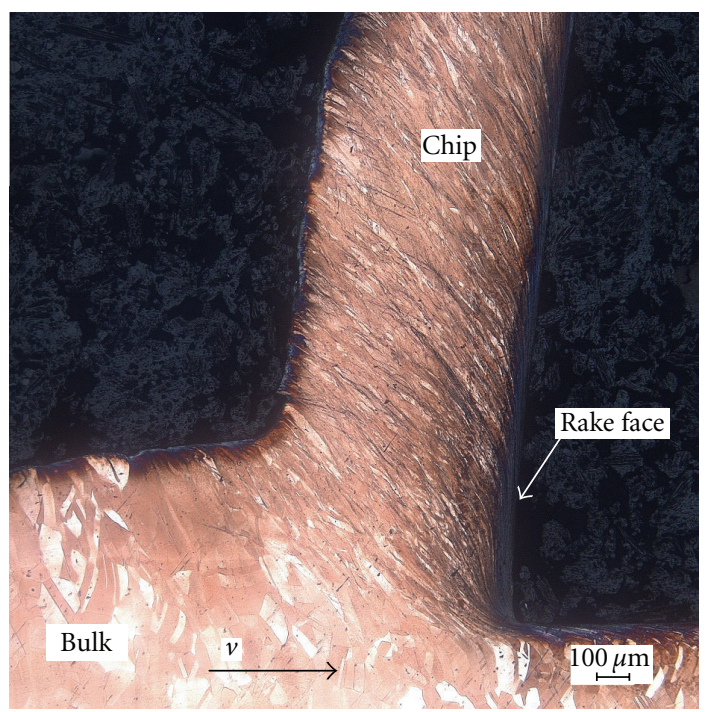

FIGURE 8: Microstructure of partially detached pure copper chip showing a narrow deformation zone and "flow-line" type chip microstructure indicative of large strain deformation in LSEM.

strain rates are much larger, is just ahead of the tool in conventional machining. However, the strain rate contours, near the tool nose in LSEM, are like a radar transmission

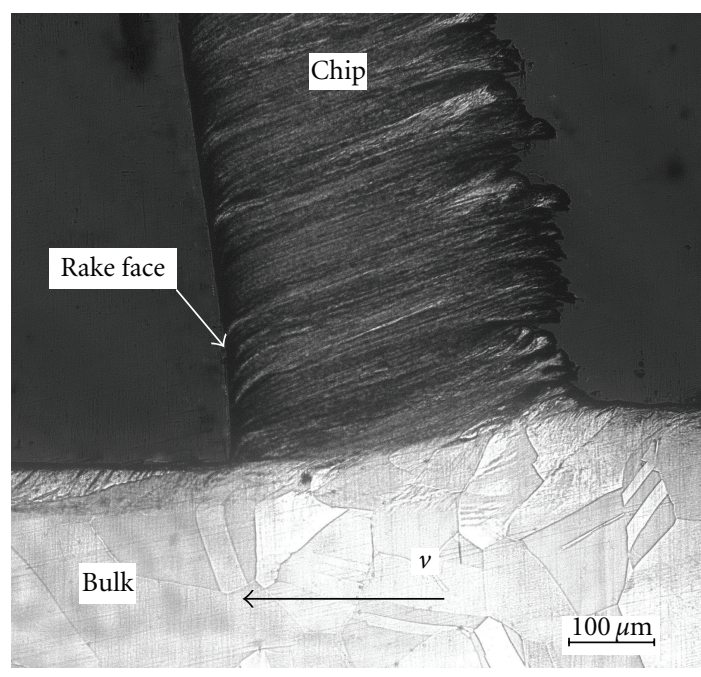

FIGURE 9: Microstructure of partially detached pure copper chip in conventional machining.

when the value of $\lambda$ is low. This concentration of strain rate in the deformation zone is perhaps even better seen in Figures $11(\mathrm{~g})$ and $11(\mathrm{~h})$, where the effective strain of a particle is mapped as it moves from the undeformed workpiece into 


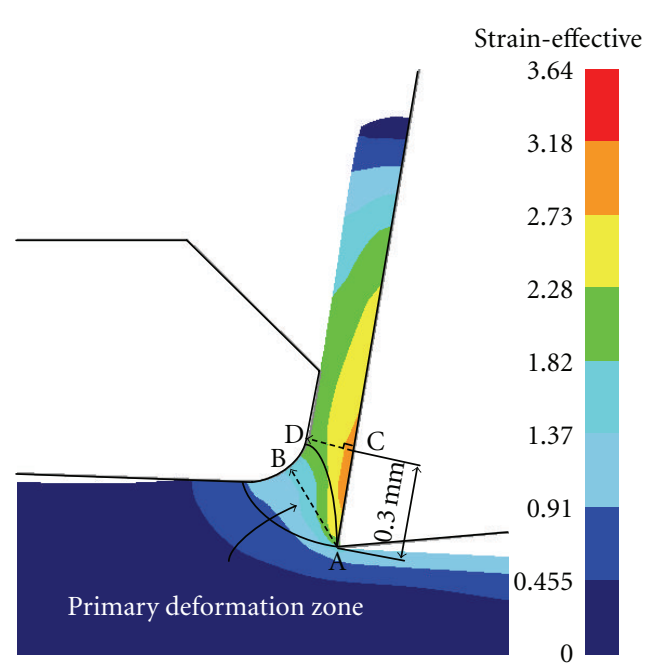

(a)

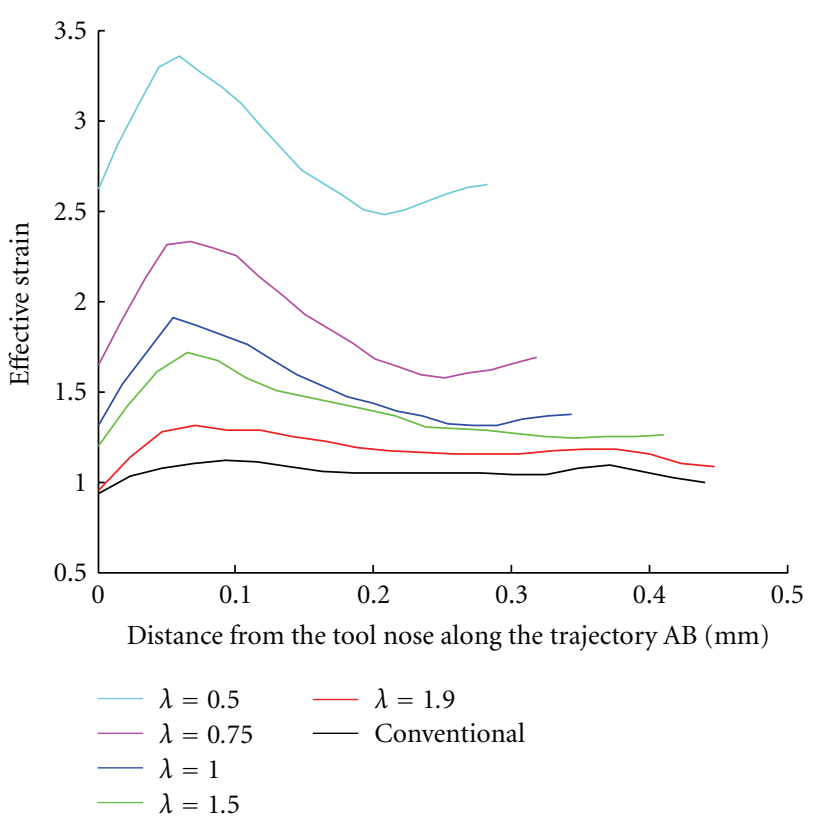

(b)

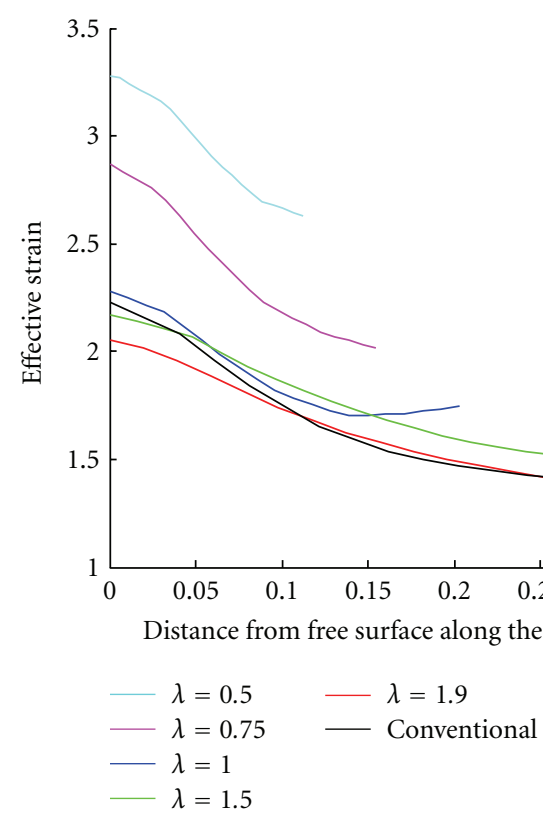

(c)

FIGURE 10: Distribution of strain through the primary deformation zone and the chip: (a) the location of the two trajectories $A B$ and $C D$; (b) variation of effective strain along the trajectory $\mathrm{AB}$ in the primary deformation zone; (c) variation of strain through the thickness of the chip.

the fully developed chip, through the primary deformation zone. The location of the trajectory is shown in Figure 11(c). The initial location of the particle is about $0.5 \mathrm{~mm}$ from the tool nose along $x$ axis and $0.05 \mathrm{~mm}$ from the tool nose along $y$ axis. It can be observed that the chip formation in LSEM is slower than that in conventional machining. It takes about $0.02 \mathrm{~s}$ to reach stability in conventional machining, while it takes about $0.03 \mathrm{~s}$ in LSEM. However, the effective strain is much larger in LSEM than in conventional machining along the specific trajectory.

Figure 12 shows SEM pictures of the typical morphology of a chip of pure copper produced by LSEM. The machining parameters used were cutting velocity of $0.052 \mathrm{~m} / \mathrm{s}$, chip compression ratio $(\lambda)$ of 1.9 , undeformed chip thickness $\left(t_{d}\right)$ of $0.2 \mathrm{~mm}$ and tool rake angle of $+10^{\circ}$. In the micrographs, the microstructure changes 


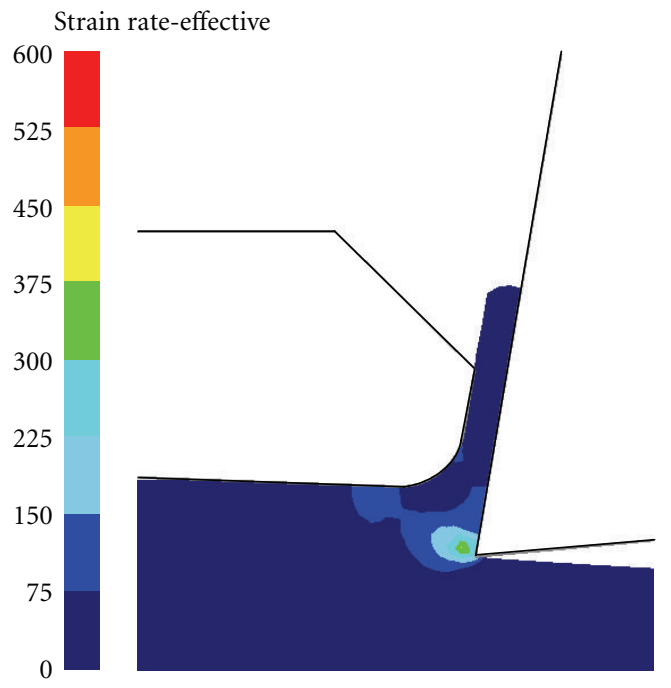

(a)

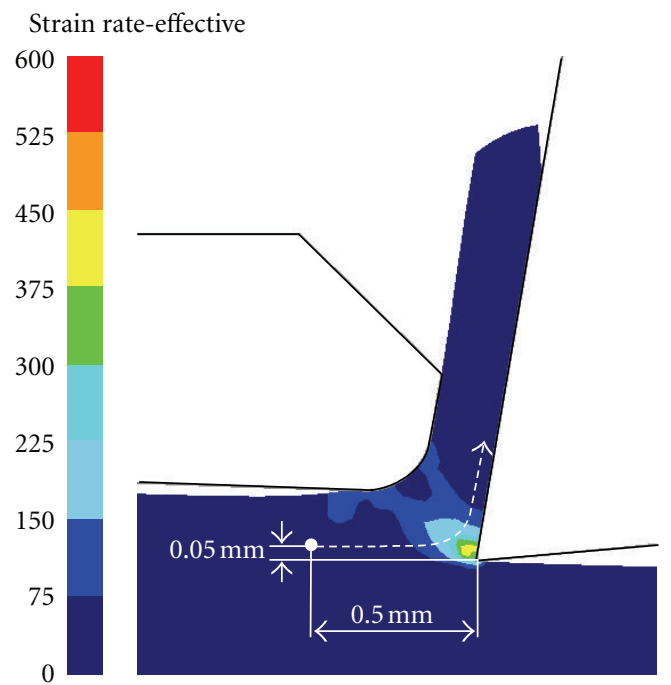

(c)

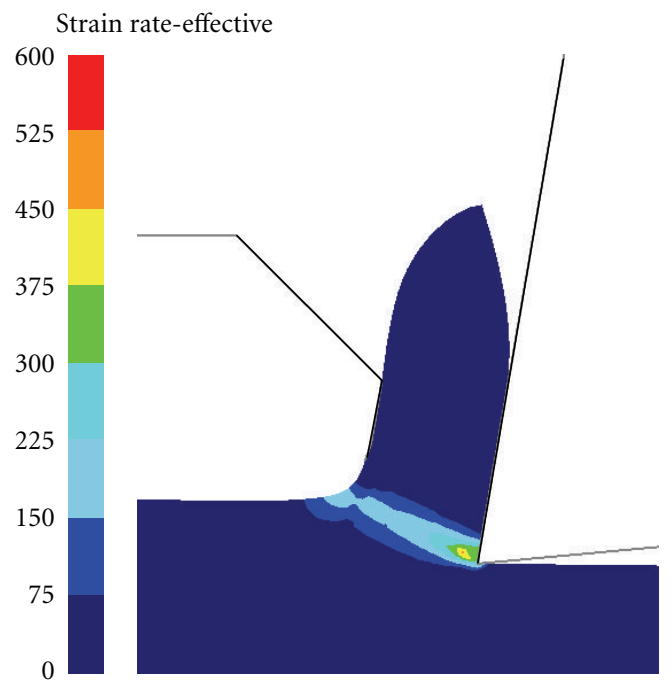

(e)

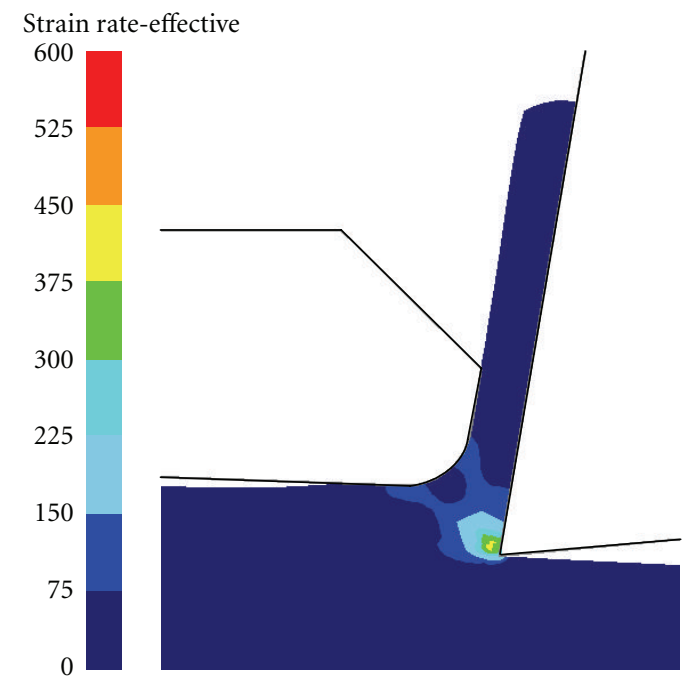

(b)

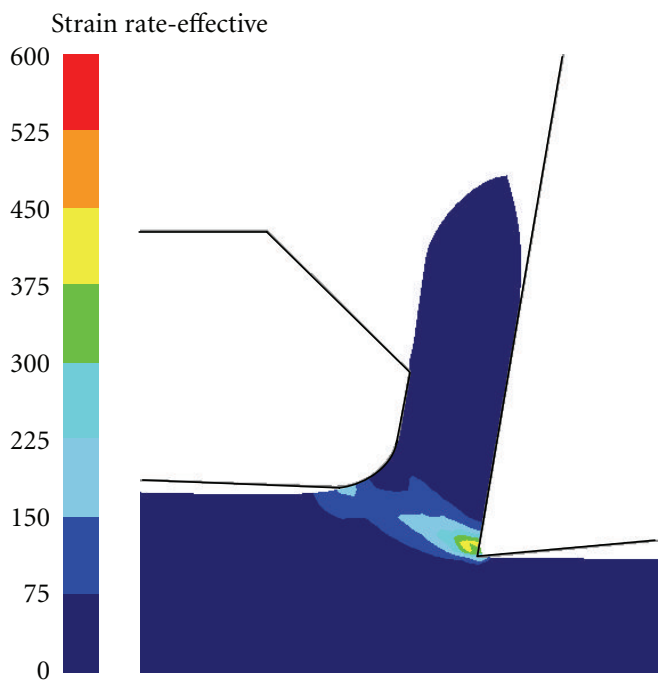

(d)

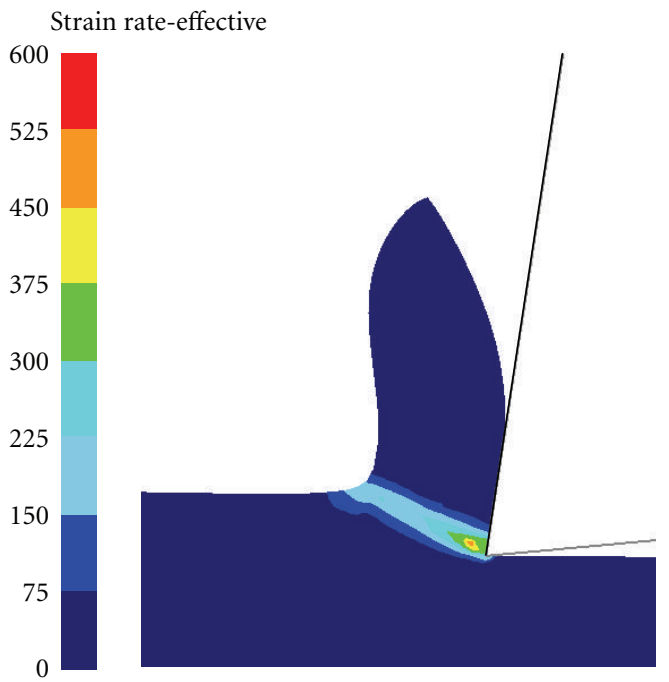

(f)

Figure 11: Continued. 


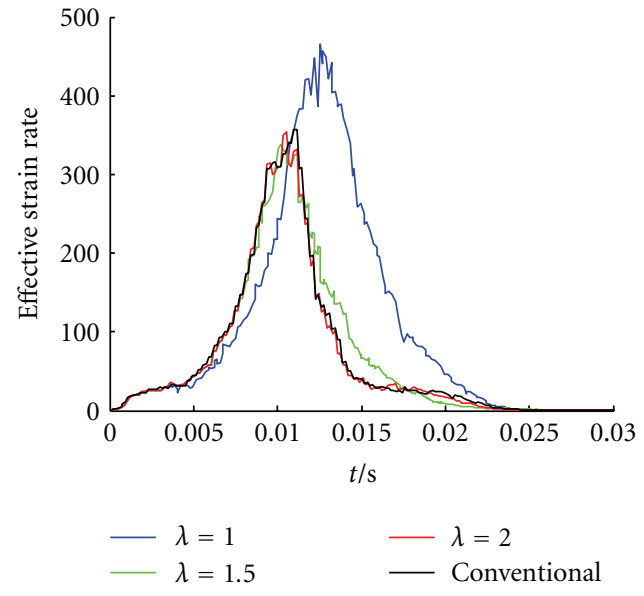

(g)

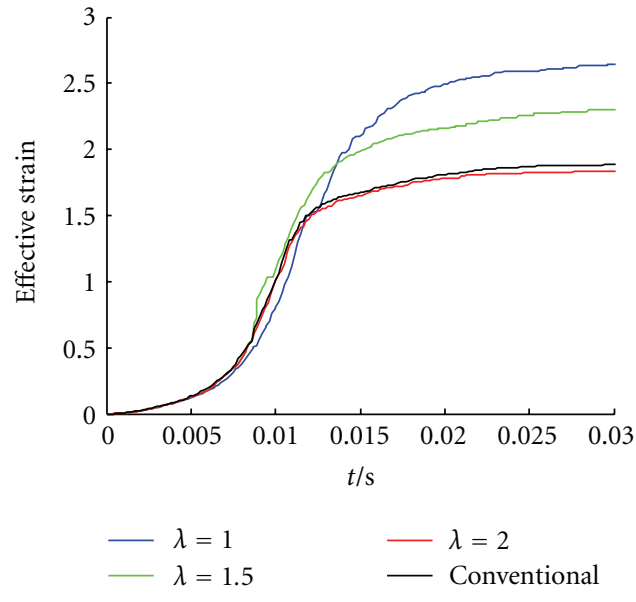

(h)

FIGURE 11: Effective strain rate distributions in LSEM and conventional machining: (a) $\lambda=0.5$; (b) $\lambda=0.75$; (c) $\lambda=1$; (d) $\lambda=1.5$; (e) $\lambda=1.9$; (f) conventional machining; (g) variation of effective strain rate along the trajectory; (h) variation of effective strain along the trajectory.

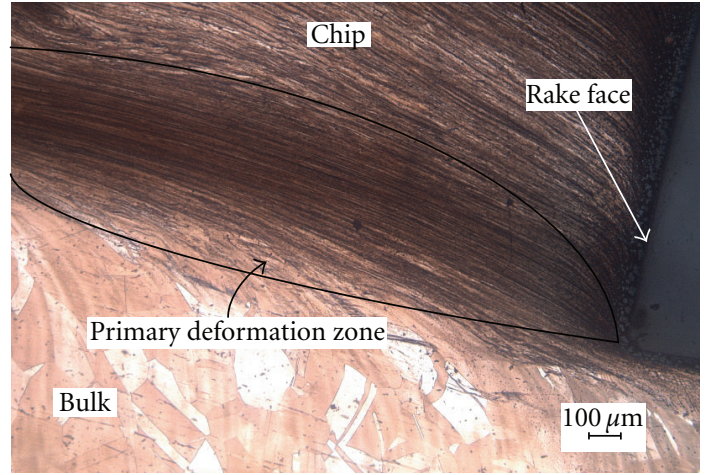

FIGURE 12: SEM micrograph of a partially formed chip of pure copper showing a primary deformation zone.

occur in the deformation zone while the chips exhibit a "flow-line-" type microstructure characteristic of material deformed to large plastic strains. It can be concluded that the numerical results agree well with the experimental results.

3.4. Cutting Force and Thrust Force. A variation of the simulated cutting and thrust force with tool travel is shown in Figures 13 and 14. The forces are analyzed with respect to time. The thrust force remains low until the time of first contact with the constraining tool. The cutting and thrust forces rise rapidly before $0.01 \mathrm{~s}$, subsequently reaching a constant value once the cutting process reaches a steadystate stage. The maximum cutting and thrust forces, seen to occur when the value of $\lambda$ is 0.5 in LSEM, are about 360 N, 365 N, respectively. As shown in Figure 13, the cutting force increases significantly as the value of $\lambda$ decreases. In Figure 14, a high thrust force is observed at small $\lambda$ as well; thus the thrust force is almost equal to the cutting force in

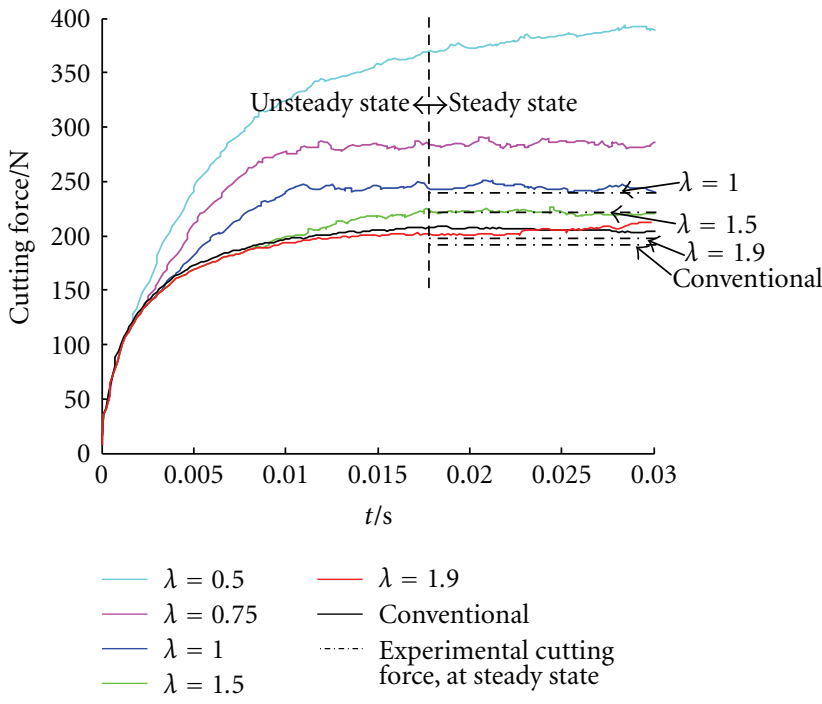

FIGURE 13: Variation of cutting force.

LSEM when the value of $\lambda$ is low. It is seen from Figure 14 that the thrust force in conventional machining, the same as in LSEM with $\lambda=1.9$, is very small. This is because the component of the friction force and extrusion force, in the $y$ direction, between the rake face and chip is very small. When $\lambda<1.925$, the addition of a constraining tool will impose new restrictions due to additional frictional forces and thrust force. These results suggest that the lower the value of $\lambda$, the larger is the thrust force, which may be a reasonable indicator for the lower limit of $\lambda$ realizable in LSEM. The numerical and the experimental cutting forces are in good agreement, as are the thrust forces. It should be also noted at lower values of $\lambda$ the chip is pushed out with greater difficulty. 


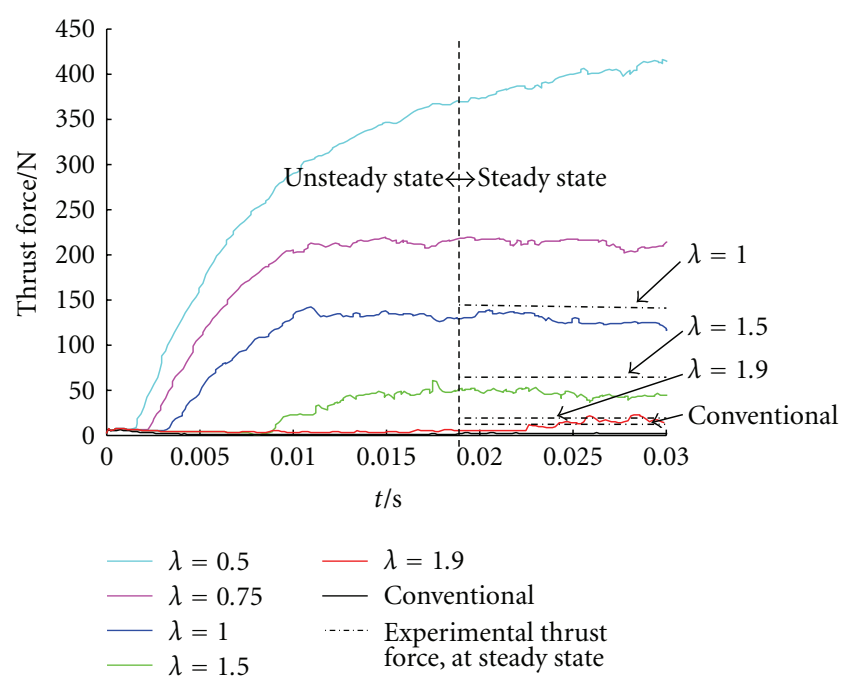

FIgURE 14: Variation of thrust force.

\section{Conclusion}

(1) A finite-element model has been developed to study large-strain extrusion machining. The finite-element simulation provide good estimates of deformation field parameters such as temperature, effective strain, effective strain rate, and limits on the chip compression ratios that can be effectively realized. It can be concluded from the investigation that LSEM can be carried out as a stable process.

(2) A series of comparisons has been made to determine the difference between LSEM and conventional machining. In contrast to what happens in conventional machining, LSEM overcomes the shortcoming of geometric uncontrollability during chip formation. LSEM has the obvious advantage over conventional machining in obtaining very high strains by changing the value of $\lambda$, thereby enabling the production of nanostructured materials.

(3) The chip compression ratio $\lambda$ provides important insights on the strain produced in the chip. As $\lambda$ becomes small, significant increases in effective strain and thrust force are observed. In order to study interactive effects of large strain deformation on microstructure and properties of materials, correlation between the deformation parameters (e.g., strain and strain rate) and machining parameters (e.g., $\lambda$ ) is necessary. When the value of the chip compression ratio is low, the deformation in primary deformation zone is severe. It can also be noted with decrease in the value of $\lambda$, it becomes more difficult for the chip to be pushed out.

(4) By conducting a trajectory, the deformation history of the material which passes through the primary zone and the chip can be obtained. The results show that grain refinement associated with the formation of nanostructured materials can be attributed to the large strains imposed in the primary deformation zone and the secondary shear zone.

\section{Acknowledgments}

This research was conducted under the support of the National Natural Science Foundation of China (50605022, 51075154), Fundamental Research Funds for the Central Universities (2012ZZ0057), Natural Science Foundation of Guangdong Province (06300160), and Zhujiang Science Technology New Stars Foundation (2011J2200066).

\section{References}

[1] R. Z. Valiev, R. K. Islamgaliev, and I. V. Alexandrov, "Bulk nanostructured materials from severe plastic deformation," Progress in Materials Science, vol. 45, no. 2, pp. 103-189, 2000.

[2] A. Mishra, V. Richard, F. Grégori, R. J. Asaro, and M. A. Meyers, "Microstructural evolution in copper processed by severe plastic deformation," Materials Science and Engineering A, vol. 410-411, pp. 290-298, 2005.

[3] M. Ravi Shankar, S. Chandrasekar, W. D. Compton, and A. H. King, "Characteristics of aluminum 6061-T6 deformed to large plastic strains by machining," Materials Science and Engineering A, vol. 410-411, pp. 364-368, 2005.

[4] S. Swaminathan, M. Ravi Shankar, S. Lee et al., "Large strain deformation and ultra-fine grained materials by machining," Materials Science and Engineering A, vol. 410-411, pp. 358363, 2005.

[5] Y. Iwahashi, Z. Horita, M. Nemoto, and T. G. Langdon, "An investigation of microstructural evolution during equalchannel angular pressing," Acta Materialia, vol. 45, no. 11, pp. 4733-4741, 1997.

[6] A. Gholinia, P. B. Prangnell, and M. V. Markushev, "Effect of strain path on the development of deformation structures in severely deformed aluminium alloys processed by ECAE," Acta Materialia, vol. 48, no. 5, pp. 1115-1130, 2000.

[7] D. Yamaguchi, Z. Horita, M. Nemoto, and T. G. Langdon, "Significance of adiabatic heating in equal-channel angular pressing," Scripta Materialia, vol. 41, no. 8, pp. 791-796, 1999.

[8] K. Nakashima, Z. Horita, M. Nemoto, and T. G. Langdon, "Influence of channel angle on the development of ultrafine grains in equal-channel angular pressing," Acta Materialia, vol. 46, no. 5, pp. 1589-1599, 1998.

[9] W. H. Huang, L. Chang, P. W. Kao, and C. P. Chang, "Effect of die angle on deformation texture of copper processed by equal channel angular extrussion," Materials Science and Engineering A, vol. 307, no. 1-2, pp. 113-118, 2001.

[10] H. S. Kim, "Finite element analysis of equal channel angular pressing using a round corner die," Materials Science and Engineering A, vol. 315, no. 1-2, pp. 122-128, 2001.

[11] T. Suo, Y. Li, Y. Guo, and Y. Liu, "The simulation of deformation distribution during ECAP using 3D finite element method," Materials Science and Engineering A, vol. 432, no. 12, pp. 269-274, 2006.

[12] Y. G. Ko, W. S. Jung, D. H. Shin, and C. S. Lee, "Effects of temperature and initial microstructure on the equal channel angular pressing of Ti-6Al-4V alloy," Scripta Materialia, vol. 48, no. 2, pp. 197-202, 2003.

[13] A. Yamashita, D. Yamaguchi, Z. Horita, and T. G. Langdon, "Influence of pressing temperature on microstructural 
development in equal-channel angular pressing," Materials Science and Engineering A, vol. 287, no. 1, pp. 100-106, 2000.

[14] S. L. Semiatin, D. P. Delo, and E. B. Shell, "Effect of material properties and tooling design on deformation and fracture during equal channel angular extrusion," Acta Materialia, vol. 48, no. 8, pp. 1841-1851, 2000.

[15] H. Jiang, Z. Fan, and C. Xie, "3D finite element simulation of deformation behavior of CP-Ti and working load during multi-pass equal channel angular extrusion," Materials Science and Engineering A, vol. 485, no. 1-2, pp. 409-414, 2008.

[16] L. De Chiffre, "Extusion-cutting," International Journal of Machine Tool Design and Research, vol. 16, no. 2, pp. 137-144, 1976.

[17] T. Hoshi and M. C. Shaw, "Cut-forming: a new method of producing wire," Journal of Engineering for Industry, Transactions of the ASME, vol. 99, no. 1, pp. 225-228, 1977.

[18] C. Shet and X. Deng, "Residual stresses and strains in orthogonal metal cutting," International Journal of Machine Tools and Manufacture, vol. 43, no. 6, pp. 573-587, 2003.

[19] J. P. Davim and C. Maranhão, "A study of plastic strain and plastic strain rate in machining of steel AISI 1045 using FEM analysis," Materials and Design, vol. 30, no. 1, pp. 160-165, 2009.

[20] S. Swaminathan, M. Ravi Shankar, B. C. Rao et al., "Severe plastic deformation (SPD) and nanostructured materials by machining," Journal of Materials Science, vol. 42, no. 5, pp. 1529-1541, 2007.

[21] S. Lee, J. Hwang, M. Ravi Shankar, S. Chandrasekar, and W. D. Compton, "Large strain deformation field in machining," Metallurgical and Materials Transactions A, vol. 37, no. 5, pp. 1633-1643, 2006.

[22] M. R. Shankar, S. Chandrasekar, A. H. King, and W. D. Compton, "Microstructure and stability of nanocrystalline aluminum 6061 created by large strain machining," Acta Materialia, vol. 53, no. 18, pp. 4781-4793, 2005.

[23] W. J. Deng, W. Xia, C. Li, and Y. Tang, "Formation of ultra-fine grained materials by machining and the characteristics of the deformation fields," Journal of Materials Processing Technology, vol. 209, no. 9, pp. 4521-4526, 2009.

[24] W. Deng, W. Xia, Y. Li, Z. Wan, and Y. Tang, "Large plastic deformation and ultra-fine grained structures generated by machining," Key Engineering Materials, vol. 375-376, pp. 21$25,2008$.

[25] M. Sevier, H. T. Y. Yang, S. Lee, and S. Chandrasekar, "Severe plastic deformation by machining characterized by finite element simulation," Metallurgical and Materials Transactions B, vol. 38, no. 6, pp. 927-938, 2007.

[26] L. De Chiffre, “Extrusion cutting of brass strips," International Journal of Machine Tool Design and Research, vol. 23, no. 2-3, pp. 141-151, 1983.

[27] M. Sevier, H. T. Y. Yang, W. Moscoso, and S. Chandrasekar, "Analysis of severe plastic deformation by large strain extrusion machining," Metallurgical and Materials Transactions A, vol. 39, no. 11, pp. 2645-2655, 2008. 

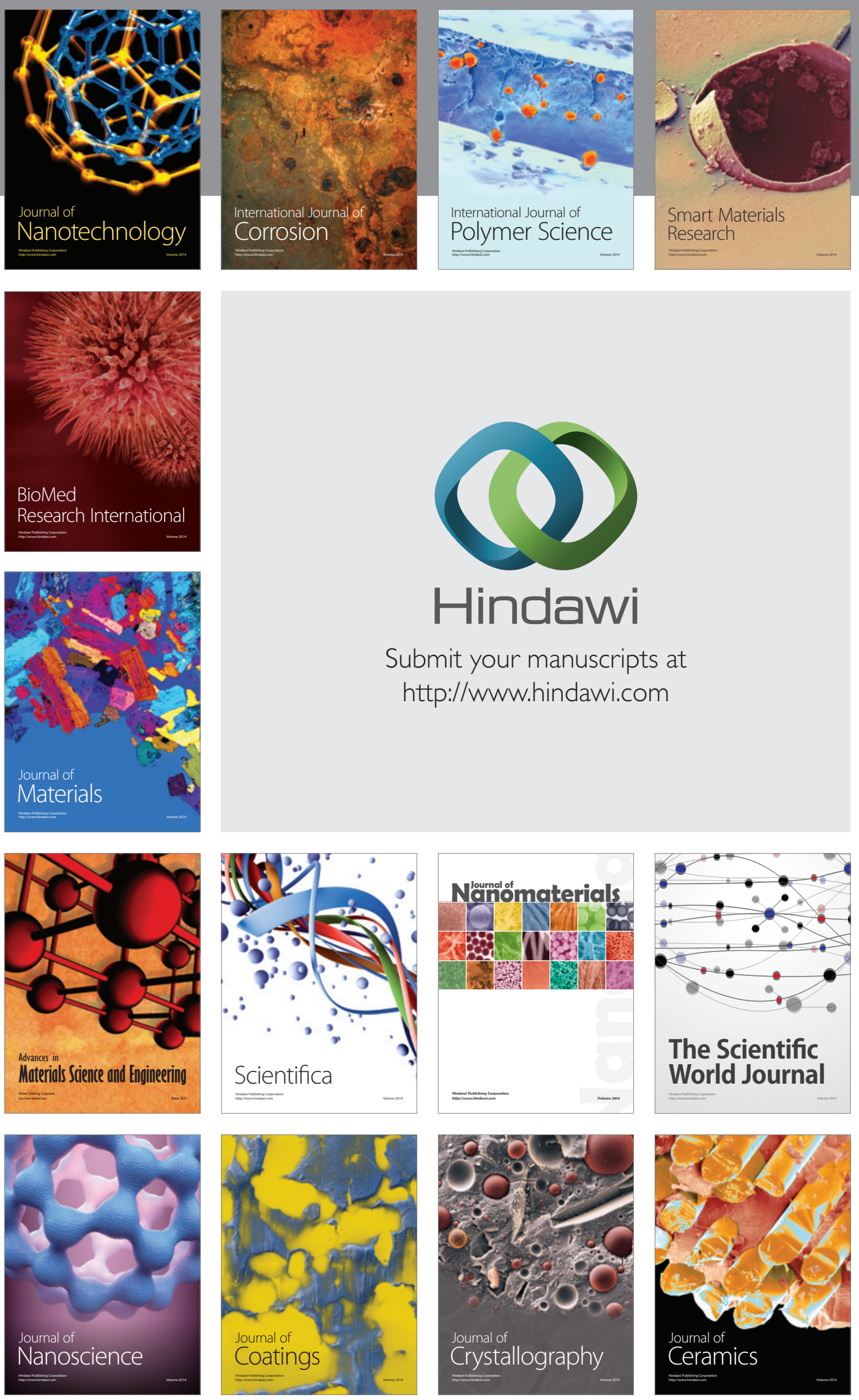

The Scientific World Journal

Submit your manuscripts at

http://www.hindawi.com

\section{World Journal}

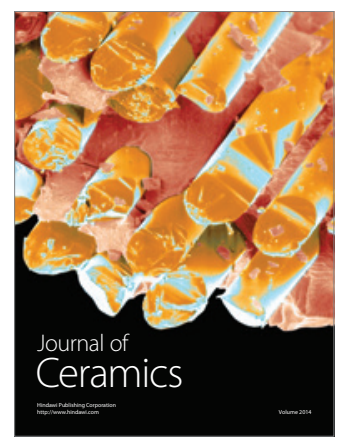

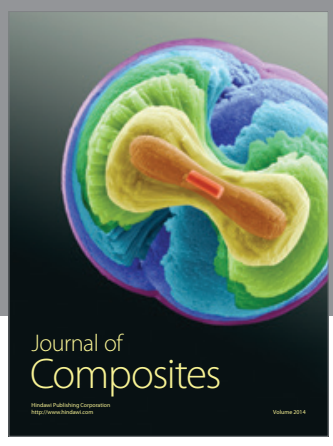
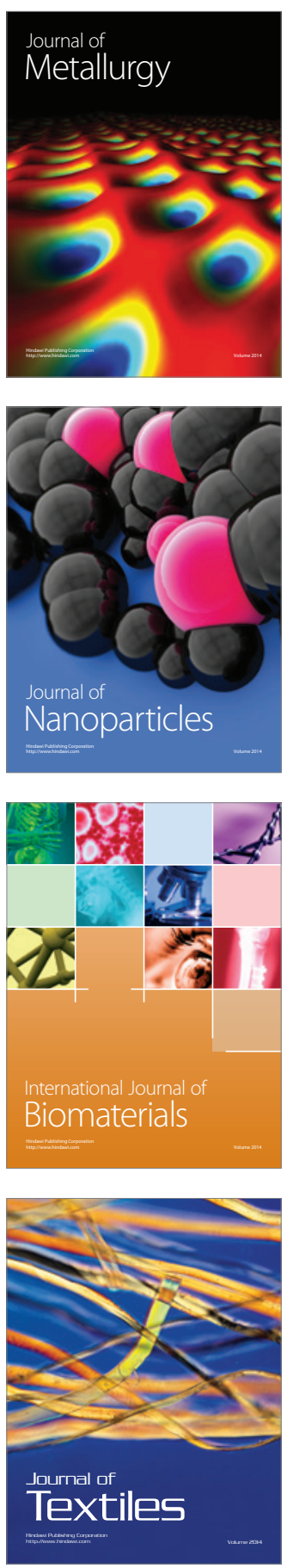